\section{Surgical Scrubs}

Note:

The following letter from Drs. Paul and Mary Anne LaRocca was received in June 1986. The Editor apologizes for the lengthy delay between receipt and publication.

\section{To the Editor:}

As clinical researchers involved in conducting rigidly controlled, statistically sound, clinical studies involving antiseptic preparations using the "glove juice" procedure, we are compelled to comment on "Brief Report: The Antiseptic Efficacy of Chlorxylenol-Containing vs. Chlorhexidine Gluconate-Containing Surgical Scrub Preparations" (Soulsby ME, Barnett JB, Maddox S: Infect Control 1986; 4:223-226).

The authors state that their study was "designed after the criteria set forth in the guidelines developed for review of antiseptics as to their safety and efficacy by the FDA." However, there are some significant deviations from these guidelines in the procedures described, and some other issues explained below that lead one to question the validity of the entire study.

1. Instead of a minimum of 30 subjects, only 12 subjects were studied. This means that only three hands were available for the 3- and 6-hour evaluations of each product, too few for reliable statistical analysis.

2. The comparison was between a prepackaged commercial Anti-Sept ${ }^{\circledR}$ sponge-brush containing a standardized amount of PCMX and a dry sponge-brush with Hibiclens ${ }^{\circledR}$ applied "as needed" (no amount given). Why didn't the authors use prepackaged Hibiclens sponge-brushes, which are also commercially available and which contain a standardized amount of chlorhexidine gluconate and a special foam to ensure that the chlorhexidine gluconate is not bound to the sponge material? The present study may have actually been a comparison of AntiSept with an inadequate amount of Hibiclens or with Hibiclens bound to the sponge material.

3. It is standard practice in "glove juice" studies to prepare tenfold serial dilutions and to perform all plating in triplicate, incorporating chemical neutralizers for the antimicrobial into the diluting fluid and plating medium. In this study, single plates were apparently used, and the authors relied upon extreme sample dilution (1 mL of 1:50 dilution added to 199 mL sampling fluid to yield $1: 10,000$ ) to eliminate concern for carryover of residual antimicrobial.

4. The data presented in the two tables are very confusing, with those of Table 2 seemingly contradicted by those of Table 1. The standard procedure is to determine the logarithm, base 10 , of each individual bacteria count and then summarize the logs in terms of means and standard deviations. Thus, the mean log counts displayed in a summary table would be the mean of individual counts. The authors, however, used a different and unusual approach. They apparently first calculated the mean of the individual raw counts and then determined the log of that mean. This value is improperly called the mean log count in Table 1. The authors summarized the raw counts rather than the $\log$ counts, resulting in a possible distortion of the data.

Published results of "glove juice" studies, including our own with Hibiclens sponge-brushes ${ }^{1,2}$ and Hibiclens $^{3}$ liquid, have indicated that if Hibiclens is used correctly and the data analyzed properly, much greater log reductions will be obtained than reported in this study, explaining why
Hibiclens is used as a standard against which other formulas are evaluated.

\section{REFERENCES}

1. LaRocca MAK, LaRocca PT: An evaluation of the antimicrobial effect of a hand sponge-brush impregnated with $4 \%$ chlorhexidine gluconate (Hibiclens). Dev Ind Microbiol 1982; 23:543-546.

2. Aly R, Maibach $\mathrm{H}$ : Comparative evaluation of chlorhexidine gluconate (Hibiclens) and povidoneiodine (E-Z Scrub) sponge/brushes for presurgical hand scrubbing. Curr Ther Res 1983; 34:740-745.

3. Peterson AF, Rosenberg A, Alatary SD: Comparative evaluation of surgical scrub preparations. Surg Grnecol Obstet 1978; 146:63-65.

Paul T. LaRocca, PhD President

Mary Anne K. LaRocca, PhD Vice President Marypaul Laboratories, Inc. Sparta, New Jersey

Dr. Michael Soulsby responds to the LaRoccas' letter:

In response to the concerns expressed by Drs. Paul and Mary Anne LaRocca, dealing with our brief report on the antiseptic efficacy of chlorxylenol-containing surgical scrub preparations, I offer the following:

Concern \#1 involves the number of subjects used and the subsequent validity of the data. Indeed, it would seem that 12 subjects would be too few for such a study, but these 12 were screened prior to the study in order to avoid normal variation among individuals. Furthermore, three plates were used to determine colony count at each sampling interval, and the standard errors of the means provided in Table 2 demonstrate the "tightness" of the data as a result of these precautions.

Concern \#2 addresses the usage of a prepackaged "finite" amount of the 3\% PCMX formulation versus an "as needed" amount of the 4\% chlorhexidine formulation, containing isopropyl alcohol. Since the chlorhexi- 